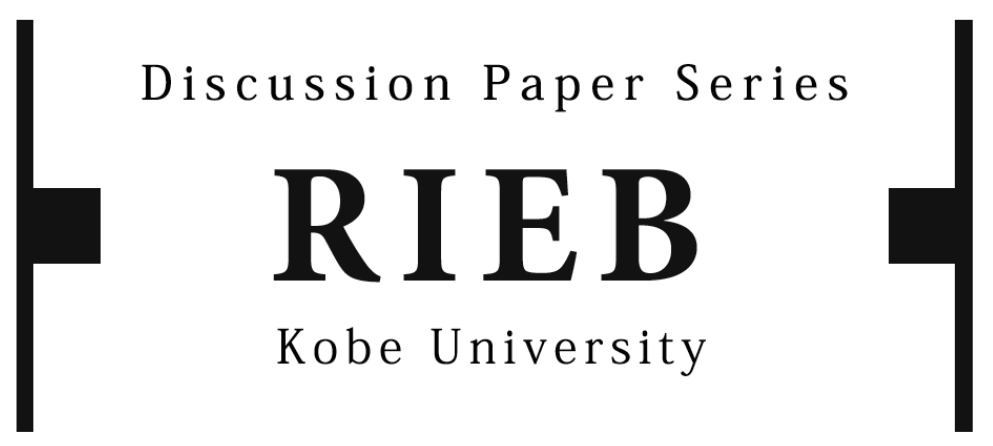

DP2016-09

Gender-specific Reference-dependent Preferences in an
Experimental Trust Game

Hiromasa TAKAHASHI

Junyi SHEN

Kazuhito OGAWA

March 9, 2016

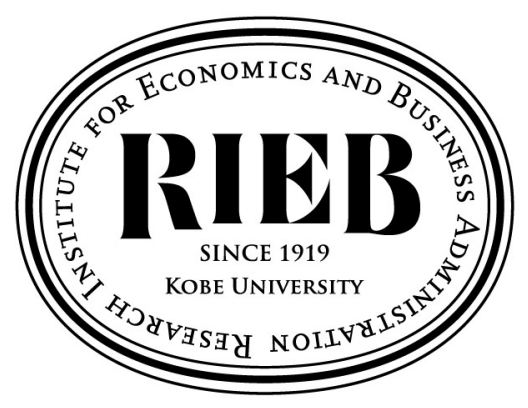

Research Institute for Economics and Business Administration Kobe University

2-1 Rokkodai, Nada, Kobe 657-8501 JAPAN 


\title{
Gender-specific reference-dependent preferences in an experimental trust game
}

\author{
Hiromasa Takahashi $^{\mathrm{a}, *}$, Junyi Shen ${ }^{\mathrm{b}, \mathrm{c}}$, and Kazuhito Ogawa ${ }^{\mathrm{d}}$ \\ ${ }^{a}$ Faculty of International Studies, Hiroshima City University, 3-4-1 Ozuka-Higashi, Asa-Minami, \\ Hiroshima 731-3194, Japan \\ ${ }^{\mathrm{b}}$ Research Institute for Economics and Business Administration, Kobe University, 2-1 Rokkodai, \\ Kobe, Hyogo 657-8501, Japan \\ ' School of Economics, Shanghai University, 99 Shangda Road, Baoshan, Shanghai 200444, \\ China \\ ${ }^{\mathrm{d}}$ Faculty of Sociology and Center for Experimental Economics, Kansai University, 3-3-35 \\ Yamate-cho, Suita, Osaka 564-8680, Japan
}

\begin{abstract}
We examine gender-specific reference-dependent preferences in a trust game experiment. Different participation fees and one question eliciting subjects' reference points were used to categorize subjects into three frames: the gain frame, gain or loss frame, and loss frame. We find that (i) men are risk-seeking in both the gain and the loss frame; (ii) women are not always more risk-averse than men; and (iii) women display other-regarding preferences only when they are in the gain frame. These results demonstrate the importance of taking account of both gender differences and reference-dependent preferences when examining individuals' economic behavior.
\end{abstract}

Keywords: Reference-dependent preference; gender difference; trust game experiment; risk preference; other-regarding preference

JEL classification: C72; C91

* Corresponding author. Tel.: +81 828301525; E-mail address: htaka@intl.hiroshima-cu.ac.jp 


\section{Introduction}

The early economic literature on decision making under risk was dominated by expected utility theory, which states that the expected utility of an act is a weighted average of the utilities of each of its possible outcomes, Kahneman and Tversky (1979) developed an alternative model called prospect theory, which is based on the following three statements. First, the value obtained from one's decisions is assigned to gains and losses rather than to final assets, and any return above one's reference point might be considered to be a gain and any return below one's reference point a loss. Second, losses generally loom larger than gains, indicating an aversion to loss. Finally, the value function is normally concave for gains and convex for losses, which implies risk aversion and risk-seeking behavior, respectively. Given the importance of linking people's reference points with their behavior, however, to the best of our knowledge, few studies have empirically investigated how people behave differently according to their reference points in decision making under risk.

Previous studies of reference points are scarce and typically focus on how an individual's reference point affects effort provision or labor supply (Abeler et al., 2011; Andersen et al., 2014; Fehr et al., 2011; Hilken et al., 2013). Abeler et al. (2011) investigated experimentally whether expectations can affect effort provision and found that effort provision is significantly different between treatments in the way predicted by models of expectation-based reference-dependent preferences: if expectations are high, subjects work longer and earn more money than if expectations are low. Andersen et al. (2014) designed a field experiment to study reference-dependent labor supply. They found that, consistent with neoclassical theory and reference-dependent preferences with endogenous reference points, workers (i.e., vendors in open air markets in their case) supply more hours when presented with an expected transitory increase in hourly wages. In contrast to the prediction of behavioral models, however, when vendors earn an unexpected windfall in the day, their labor supply does not respond.

In addition to the importance of reference points, gender differences in behavior have been studied in many economic experiments. Croson and Gneezy (2009) reviewed the literature and identified robust differences in three main sections: risk preferences, social (other-regarding) preferences, and competitive preferences. They concluded that (i) women are more risk-averse than men; (ii) the social preferences of women are more situationally specific than those of men; women are neither more nor less socially oriented, but their social preferences are more malleable; and (iii) women are more averse to competition than men. Acknowledging these gender differences, in the present study we design a trust game experiment to investigate gender-specific reference-dependent preferences. Since studies taking account of both gender differences and reference-dependent preferences are extremely scarce, we expect to provide some new insights into the body of knowledge on this topic. 
In the best-known version of the trust game (Berg et al., 1995), an agent (called a trustor) is asked what proportion of a given endowment he or she is willing to entrust to a complete stranger (called a trustee) with the expectation that the latter will reciprocate by returning more money than he or she initially received. The accounting is made viable by the fact that any investment made by the sender is multiplied by a factor of more than one (tripled in our experiment) before reaching the recipient. While the solution predicted by game theory is that both trustor and trustee have no incentive to make any positive offers, Pareto efficiency would require the sender to trust and the recipient to be trustworthy (i.e., if the sender makes a positive offer and the receiver returns an amount not lower than the offer received, both parties are better off or at least not worse off). Although the typical interpretation of the trust game labels the sender's behavior as "trust" and the receiver's behavior as "trustworthiness," it should be noted that trust or trusting behavior carries the risk of negative consequences if the trust is misplaced and met by untrustworthy behavior. Therefore, the trustor's behavior can also, to some extent, exhibit his or her risk preference.

Previous studies investigating gender differences in trust games have provided mixed findings on both trustor and trustee behavior. On the trustor behavior, while a number of studies have found no gender differences in sending behavior (Bohnet, 2007; Bohnet et al., 2010; Cox and Deck, 2006; Croson and Buchan, 1999; Schwieren and Sutter, 2008), other works have shown that men are more trusting or risk-seeking than women (Buchan et al., 2008; Chaudhuri and Gangadharan, 2007; Garbarino and Slonim, 2009; Snijders and Keren, 2001). Only a few studies have found that women are more trusting or risk-seeking than men (Bellemare and Kröger, 2003; Bohnet et al., 2010). In addition, while some authors have found no gender differences in trustworthiness or reciprocity (Bohnet, 2007; Cox and Deck, 2006; Innocenti and Pazienza, 2006), others have shown that women are more reciprocal than men (Buchan et al., 2008; Chaudhuri and Gangadharan, 2007; Croson and Buchan, 1999; Schwieren and Sutter, 2008; Snijders and Keren, 2001). Indeed, only Bellemare and Kröger (2003) found that men are more reciprocal than women.

We conducted a one-shot trust game experiment. Before starting the experiment, we asked subjects how much they expected to earn in the experiment. This amount of expected earnings served as the subject's reference point. In addition, three treatments based on different participation fees $(0,500$, and $1000 \mathrm{JPY})$ were designed to help categorize subjects into three frames: the gain frame, gain or loss frame, and loss frame. Our main findings are that (i) male subjects are risk-seeking in both the gain frame and the loss frame; (ii) women are not always more risk-averse than men; and (iii) women display other-regarding preferences only when they are in the gain frame.

The remainder of the paper is organized as follows. Section 2 describes the issues related to 
the experiment. The results of the experiment are presented in Section 3. Finally, Section 4 discusses the results and suggests several possible directions for future studies.

\section{Experimental design}

Our one-shot trust game experiment had three treatments according to the participation fee: 0, 500, and 1000 JPY. The 0 and 500 JPY treatments consisted of five sessions each and the 1000 JPY treatment consisted of eight sessions. All experimental sessions were conducted at Kansai University from June 2014 to September 2015. We confirmed in advance and guaranteed that one subject was allowed to take part in only one experimental session. As a result, 420 subjects participated in the experiment (199 men). Table 1 provides detailed information on the number of subjects in each treatment. Subjects were assigned to be either a trustor or a trustee and then paired randomly. To maintain anonymity between trustors and trustees, they were arranged in different classrooms when they arrived and stayed there during the experiment. In each classroom, subjects were first asked to write down their answers about how much they would expect to earn from the upcoming experiment. After these answers were collected by the experimenter, subjects received written experimental instructions, which were first read individually by subjects and then aloud by a Japanese-speaking experimenter. ${ }^{1}$

Both the trustors and the trustees received an envelope containing an endowment of 600 JPY (i.e., five 100 -yen coins, one 50 -yen coin, and five 10 -yen coins). ${ }^{2}$ The trustors had to decide on the amount to transfer to their counterparts. After deciding the amount, the trustors were asked to put the money being transferred into another envelope provided by the experimenter. Then, an experimenter took them to an empty room and tripled the transferred amount. After that, the experimenter took these envelopes to the trustees' classroom and distributed them to the corresponding trustees. The trustees learned the trustors' transfer and decided how much to give back to their counterparts. After deciding the amount, the trustees were asked to put the money in the same envelope; the experimenter then took these envelopes to the trustors' classroom and distributed to the corresponding trustors. After all subjects had completed their record sheets, the experiment was finished. ${ }^{3}$

\footnotetext{
${ }^{1}$ Only the experimental instructions of the session that offered subjects a 500 JPY participation fee are provided in Appendix A. Those of the other sessions were similar.

${ }^{2}$ In the 500 and 1000 JPY treatments, both trustors and trustees received one additional envelope containing their participation fee.

${ }^{3}$ In seven sessions, poker chips were used instead of cash. In these sessions, the earned chips were changed to real money at the end of the experiment. We used poker chips to investigate whether there was a tangibility effect of cash (Reinstein and Riener, 2012; Shen and Takahashi, 2013; Wang and Qin, 2015) in our experiment. However, because we found no statistical differences in either trustor or trustee behavior between poker chip and cash sessions, we pooled these data in our
} 
Communication was prohibited during the experiment, with subjects told that the experiment would be terminated immediately if they communicated with one another. Each session of the experiment lasted for about 45 minutes and subjects earned, on average, 1395 JPY (about 12.67 USD, using 1 USD $=110 \mathrm{JPY}$ ). ${ }^{4}$

\section{Experimental results}

\subsection{Preliminary results}

Table 2 reports the mean values of subjects' gender-specific reference points, transfer rates, and return rates. The transfer rate is calculated by dividing the trustor's transfer amount by the endowment of $600 \mathrm{JPY}$, and the return rate is calculated by dividing the trustee's return amount by the received tripled amount. As shown in the table, the mean value of the reference point for male subjects is $1383.67 \mathrm{JPY}$, which is significantly higher than that for female subjects (1223.98 JPY). This means that, on average, men expected to earn more in the experiment than women. With respect to the trustor's transfer behavior, male subjects averagely transferred half of their endowments, which is significantly higher than that of female subjects. However, there is no significant difference observed in the trustee's return behavior, either in the return rate or in the return amount. ${ }^{5}$

\subsection{Results of categorizing subjects based on their reference points}

Figures $1 \mathrm{a}$ and $1 \mathrm{~b}$ present the images of categorizing trustors and trustees, respectively. Trustors were categorized into the Gain frame, Loss frame, or Gain or Loss frame by comparing their reference points with participation fee and "participation fee + endowment." The trustors whose reference points were smaller than the participation fee were categorized into the Gain frame. Trustors categorized in the Gain frame would be so even though they transferred all the endowment (600 JPY) and got nothing back. On the other hand, the trustors whose reference points were larger than "participation fee + endowment" were categorized into the Loss frame. Trustors categorized in the Loss frame would be so if they did not transfer any amount for expecting some returns. The remaining trustors were categorized into the Gain or Loss frame.

empirical analysis.

${ }^{4}$ The trustor's payoff is calculated as the sum of "600 JPY - his/her transfer + the amount given back by the trustee + his/her participation fee." The trustee's payoff is calculated as the sum of "600 JPY + the tripled amount of the trustor's transfer - the amount that he/she gave back + his/her participation fee.”

${ }^{5}$ The results of the three treatments are provided in Appendix B. 
Whether those categorized in Gain or Loss frame would be in a gain frame or a loss frame was dependent on their transfer amounts and the returns they would receive from the trustees. In particular, they would be in a gain frame if they transferred nothing. Similarly, trustees were also categorized into the Gain frame, Loss frame, and Gain or Loss frame by comparing their reference points with "participation fee + endowment" and "participation fee + endowment + tripled transfer." Trustees categorized in the Gain frame would be so even though they returned all received tripled transfers. Trustees categorized in the Loss frame would be so even if they returned nothing. For trustees categorized in the Gain or Loss frame, whether they would be in the gain frame or the loss frame was dependent on their return amounts. That is, they could decide in which frame they would be.

Based on the above categorization, Table 3 reports the descriptive statistics of the trustor's transfer rate specified by category and gender. To further clarify the distributions of transfer behavior among the different categories, the cumulative distribution functions of the transfer rate for male and female subjects are also presented in Figure 2. As shown in this figure, for male trustors the distribution of the transfer rate in the Gain or Loss frame is stochastically dominated by those in the Gain frame and Loss frame, while for female trustors there seems no obvious domination among these three frames.

The mean and median values reported in Table 3 support the visual evidence. Men in the Gain frame and Loss frame significantly transferred more than men in the Gain or Loss frame ( $t$ test and Wilcoxon rank sum test, both $p$ values $<0.01$ ). Further, there is no significant difference in the transfer rate between men in the Loss frame and in the Gain frame ( $t$ test and Wilcoxon rank sum test, both $p$ values $>0.48$ ). In addition, the transfer rate of female trustors did not vary among the different categories ( $t$ test and Wilcoxon rank sum test, all $p$ values $>0.90$ ). With regard to the comparison between men and women, we found that male trustors significantly transferred more than women in the Gain frame and in the Loss frame ( $t$ test and Wilcoxon rank sum test, both $p$ values $<0.001$ in the Gain frame and both $p$ values $<0.05$ in the Loss frame), but not in the Gain or Loss frame ( $t$ test and Wilcoxon rank sum test, both $p$ values $>0.90$ ).

Table 4 provides the descriptive statistics of the trustee's return rate specified by category and gender, and Figure 3 presents the cumulative distribution functions of the return rate for male and female subjects. As shown in the figure, for female trustees the distribution of the return rate in the Gain frame stochastically dominates those in the Gain or Loss frame and Loss frame; for male trustees there seems no obvious domination among these three frames. The results obtained from the $t$ test and Wilcoxon rank sum test suggest that the return rate of men did not vary among categories (all $p$ values $>0.26$ ). Moreover, women in the Gain frame significantly returned more than women in the Gain or Loss frame (both $p$ values $<0.05$ ) and in the Loss frame (both $p$ values $<0.01$ ). In addition, there is no significant difference in the return 
rate between women in the Gain or Loss frame and in the Loss frame (both $p$ values > 0.26). Finally, women significantly returned more than men in the Gain frame (both $p$ values $<0.05$ ) and in the Gain or Loss frame (both $p$ values $<0.05$ ), but not in the Loss frame (both $p$ values $>$ $0.21)$.

\section{Discussion and conclusion}

This study examined gender-specific reference-dependent preferences in a trust game experiment. The three main results are somewhat different to those in previous studies. First, prospect theory, proposed by Kahneman and Tversky (1979), suggests that people are risk-seeking for losses and risk-averse for gains; however, we found that men sent more in both gain and loss frames, while women did not. This result exhibits that men can also be risk-seeking even in the gain frame. Although its robustness needs to be verified by further research, this finding could be plausible because when risk-seeking men receive payoffs above their expectations, they might be willing to take the risk/return tradeoff with the "profits" (certain payoffs minus expected earnings) to pursue more gains. However, the result that men sent less in the Gain or Loss frame suggests the loss aversion property of their preference.

Second, although Croson and Gneezy (2009) concluded that women are more risk-averse than men, our results indicate that this is not always the case. In our trust game experiment, we did find that women are more risk-averse than men in the Gain frame and the Loss frame. However, in the Gain or Loss frame there is no difference between men and women in risk preferences. This finding implies that the gender difference in risk preferences could be situationally specific according to in which frame they are.

Third, the result that women in the Gain frame significantly returned more than women in the Gain or Loss frame and in the Loss frame shows that women are not always reciprocal; they display other-regarding preferences only when they are in the gain frame. In the other two frames, the other-regarding preferences of women may be dominated by their loss aversion preference. Therefore, it seems that similar to the gender difference in risk preferences, women's other-regarding preferences are also situationally specific.

The above findings demonstrate the importance of interacting gender differences with reference-dependent preferences when examining individuals' economic behavior. Because studies that account for both these issues are scarce, future research is thus needed to verify our findings and provide more new insights into the body of knowledge on this topic.

Finally, the trust game used in our experiment allows us to observe both trustor and trustee behavior in the Gain frame and the Loss frame. However, behavior in the Gain or Loss frame is difficult to analyze because whether subjects are in the gain frame or in the loss frame is 
dependent on their experimental behavior. Therefore, a new theoretical framework that serves as directions for experiments should be considered in future studies. In addition, in our experiments we studied a sample of student subjects. However, research with non-student pools suggests that students might behave differently to non-student subjects. Therefore, future studies could be conducted by recruiting members from other sections of society.

\section{Acknowledgments}

The financial support from the Japanese Ministry of Education, Culture, Sports, Science and Technology through Grants-in-aid for Scientific Research (C) 25380234 and 15K03353 is gratefully acknowledged. For recruiting subjects, the Centre for Experimental Economics, Kansai University helped a lot. All the views expressed in this paper and any errors are the sole responsibility of the authors.

\section{References}

Abeler, J., Falk, A., Goette, L., and Huffman, D. (2011) Reference point and effort provision. American Economic Review, 101, 470-492.

Andersen, S., Brandon, A., Gneezy, U., and List, J. A. (2014) Toward an understanding of reference-dependent labor supply: Theory and evidence from a field experiment. NBER Working Paper Series No. 20695.

Bellemare, C. and Kröger, S. (2007) On representative trust. European Economic Review, 51(1), 183-202.

Berg, J., Dickhaut, J., and McCabe, K. (1995) Trust, reciprocity and social history. Games and Economic Behavior, 10, 122-142.

Bohnet, I. (2007) Why women and men trust others? In Economics and Psychology: A Promising New Cross-Disciplinary Field, ed. Bruno S. Frey and Alois Stutzer, 89-110. Cambridge and London: MIT Press.

Bohnet, I., Herrmann, B., and Zeckhauser, R. (2010) Trust and the reference points for trustworthiness in gulf and western countries. Quarterly Journal of Economics, 125(2), 811-828.

Buchan, N. R., Croson, R., and Solnich, S. J. (2008) Trust and gender: An examination of behavior and beliefs in the investment game. Journal of Economic Behavior and Organization, 68(3-4), 466-476.

Chaudhuri, A. and Gangadharan, L. (2007) An experimental analysis of trust and 
trustworthiness. Southern Economic Journal, 73(4), 959-985.

Cox, J. C. and Deck, C. A. (2006) When are women more generous than men? Economic Inquiry, 44(4), 587-598.

Croson, R. and Buchan, N. R. (1999) Gender and Culture: International experimental evidence from trust games. American Economic Review, 89(2), 386-391.

Croson, R. and Gneezy, U. (2009) Gender differences in preferences. Journal of Economic Literature, 47(2), 1-27.

Fehr, E., Hart, O., and Zehnder, C. (2011) Contracts as reference points - experimental evidence. American Economic Review, 101, 493-525.

Garbarino, E. and Slonim, R. (2009) The robustness of trust and reciprocity across a heterogeneous U.S. population. Journal of Economic Behavior and Organization, 69(3), 226-240.

Hilken, K., Rosenkranz, S., Jaegher, K., and Jeders, M. (2013) Reference points, performance and ability: A real effort experiment on framed incentive schemes. Discussion Paper Series 13-15, Utrecht School of Economics, Tjalling C. Koopmans Research Institute.

Innocenti, A. and Pazienza, M. G. (2006) Altruism and gender in the trust game. University of Sienna Department of Economics Working Paper 5/2006.

Kahneman, D. and Tversky, A. (1979) Prospect theory: An analysis of decision under risk. Econometrica, 47(2), 263-292.

Reinstein, D. and Riener, G. (2012) Decomposing desert and tangibility effects in a charitable giving experiment. Experimental Economics, 15, 229-240.

Schwieren, C. and Sutter, M. (2008) Trust in cooperation or ability? An experimental study on gender differences. Economics Letters, 99(3), 494-497.

Shen, J. and Takahashi, H. (2013) A cash effect in ultimatum game experiments. Journal of Socio-Economics, 47, 94-102.

Snijders, C. and Keren, G. (2001) Do you trust? Whom do you trust? When do you trust? Advances in Group Processes, 18, 129-160.

Wang, S. and Qin, X. (2015) The effect of digitalization on penalty payments: An experimental investigation. Journal of Neuroscience, Psychology, and Economics, 8(4), 250-261. 


\section{Appendices}

\section{A. Experimental instructions}

\section{A.1. For trustors in the session with a 500 JPY participation fee}

Procedure of the experiment

We will now explain the procedure of the experiment. Please read carefully and make sure you understand.

- In another room (lecture room A304), there are people who will be paired with you. You will never be informed of the identity of these counterparts.

- This experiment will be carried out only once. ${ }^{6}$

(1. At the beginning of the experiment, both you and your counterpart receive a $500 \mathrm{JPY}^{7}$ participation fee in an envelope. Note that this money is independent of your performance in the experiment.

(2). Then, you receive another envelope (hereinafter referred to as Envelope A) containing 600 JPY and an empty envelope (hereinafter referred to as Envelope B) on which a sequence of characters is printed.

(3). You must decide how much you are going to transfer to your counterpart. Please decide the amount from 0 JPY to 600 JPY in units of 10 JPY.

(4). After you make your decision, please write the amount in the field "Your transfer" of the record sheet. Then, put the money being transferred into Envelope B and put the remainder into Envelope A.

(5). The experimenter will collect Envelope B, triple your transferred amount, and take Envelope B containing the tripled amount of money to your counterpart.

(6). Note that your counterpart also receives $600 \mathrm{JPY}$ as you do. Your counterpart will decide how much to give back to you from the sum of the tripled amount and his/her $600 \mathrm{JPY}$.

(7). Then, the experimenter will bring Envelope B containing the money that your counterpart gives back to you. Please check the amount and write it in the field "Amount given back by the counterpart" on the record sheet.

8. Please calculate your total payoff, which is the sum of "600 JPY - your transfer + the amount given back by your counterpart + 500 JPY participation fee" and write the amount in the field "Your payoff" of the record sheet.

\footnotetext{
${ }^{6}$ When using poker chips, we also provided information that explained the number on the chips meant the yen amount and that they would be changed to cash after the experiment.

7 "500 JPY" was replaced with "poker chips worth 500 JPY" in the chip sessions. The following descriptions of the amount of money were replaced in the same way.
} 
(9. Finally, check whether the above amount is consistent with the cash you hold. Please take the money and leave the room quietly if it is consistent.

\section{A.2. For trustees in the session with a $500 \mathrm{JPY}$ participation fee}

Procedure of the experiment

We will now explain the procedure of the experiment. Please read carefully and make sure you understand.

- In another room (lecture room A303), there are people who will be paired with you. You will never be informed of the identity of these counterparts.

- This experiment will be carried out only once.

(1). At the beginning of the experiment, both you and your counterpart receive a 500 JPY participation fee in an envelope. Note that this money is independent of your performance in the experiment.

(2). Then, you receive another envelope (hereinafter referred to as Envelope A) containing 600 JPY.

(3). Your counterpart also receives $600 \mathrm{JPY}$ and decides how much to transfer to you from the $600 \mathrm{JPY}$.

(4). The experimenter will triple the transferred amount and put it into an envelope (hereinafter referred to as Envelope B) on which "०००×3=\#\#\#" is written. 000 is the transferred amount and \#\#\# is the tripled amount. Please confirm the transferred and tripled amounts and write them in the fields "The transferred amount" and "The tripled amount" on the record sheet, respectively.

(5). You are to decide how much to give back to your counterpart. After deciding the amount, please write it in the field "Amount giving back" on the record sheet. Then, put the money being given back into Envelope B and put the remainder into Envelope A.

(6). The experimenter will collect Envelope B and take it to your counterpart.

(7). Please calculate your total payoff which is the sum of "600 JPY + the tripled amount - the amount that you give back to your counterpart + 500 JPY participation fee" and write the amount in the field of "Your payoff" on the record sheet.

8. Finally, check whether the above amount is consistent with the cash you hold. Please take the money and leave the room quietly if it is consistent. 


\section{B. Results of three treatments with different participation fees}

\begin{tabular}{|c|c|c|c|c|}
\hline & & $\begin{array}{l}\text { Participation fee } 1000 \\
\text { JPY }\end{array}$ & $\begin{array}{c}\text { Participation fee } 500 \\
\text { JPY }\end{array}$ & $\begin{array}{l}\text { Participation } \\
\quad \text { fee } 0\end{array}$ \\
\hline \multicolumn{5}{|c|}{ Transfer rate } \\
\hline \multirow[t]{3}{*}{ Female } & Frequency & 36 & 36 & 37 \\
\hline & Mean & 0.374 & 0.334 & 0.368 \\
\hline & Median & 0.333 & 0.275 & 0.333 \\
\hline \multirow[t]{3}{*}{ Male } & Frequency & 44 & 27 & 30 \\
\hline & Mean & 0.475 & 0.451 & 0.665 \\
\hline & Median & 0.412 & 0.417 & 0.825 \\
\hline \multicolumn{5}{|l|}{ Return rate } \\
\hline \multirow[t]{3}{*}{ Female } & Frequency & 41 & 32 & 39 \\
\hline & Mean & 0.384 & 0.445 & 0.329 \\
\hline & Median & 0.333 & 0.456 & 0.333 \\
\hline \multirow[t]{3}{*}{ Male } & Frequency & 39 & 31 & 28 \\
\hline & Mean & 0.286 & 0.28 & 0.341 \\
\hline & Median & 0.167 & 0.206 & 0.267 \\
\hline
\end{tabular}

Notes: Concerning the gender differences in different treatments, the transfer rate of men in the 0 JPY treatment is significantly higher than that of women $(p=0.0006$ in $t$ test and $p=0.003$ in Wilcoxon rank sum test), while there are no differences in the other two treatments (all $p$ values $>$ 0.10). The return rate of women in the 500 and $1000 \mathrm{JPY}$ treatments are higher than those of men (participation fee 500 JPY: $p=0.012$ in $t$ test and $p=0.009$ in Wilcoxon rank sum test; participation fee 1000 JPY: $p=0.09$ in $t$ test and $p=0.06$ in Wilcoxon rank sum test), while there is no difference in the $0 \mathrm{JPY}$ treatment (both $p$ values $>0.10$ ). In addition, men in the $0 \mathrm{JPY}$ treatment of transfer significantly more than those in the other two treatments (all $p$ values $<0.05$ using both $t$ test and Wilcoxon rank sum test), while there is no treatment effect in the transfer rate of women (all $p$ values $>0.10$ ). The unique significant result for return rates exists in the comparison between women in the $500 \mathrm{JPY}$ treatment and women in the $0 \mathrm{JPY}$ treatment, with the previous higher than the latter $(p=$ 0.052 in $t$ test and $p=0.03$ in Wilcoxon rank sum test). 
Table 1. Number of subjects in each experimental treatment

\begin{tabular}{lcccc}
\hline & $\begin{array}{c}\text { Participation } \\
\text { fee } 0\end{array}$ & $\begin{array}{c}\text { Participation fee 500 } \\
\text { JPY }\end{array}$ & Participation fee 1000 & Total \\
\hline Female & 76 & 68 & JPY & \\
Male & 58 & 58 & 77 & 221 \\
Total & 134 & 126 & 83 & 199 \\
\hline
\end{tabular}

Note: The pairwise two-tailed proportion test indicates that there are no significant differences in the ratio of men to women across treatments (all $p$ values $>0.10$ ).

Table 2. Mean values of the reference point, transfer rate, and return rate by gender

\begin{tabular}{lcccc}
\hline & Male subjects & Female subjects & $t$ value & $p$ value (two-tailed) \\
\hline Reference point (JPY) & 1383.67 & 1223.98 & 2.82 & 0.0050 \\
Transfer rate & 0.504 & 0.380 & 3.84 & 0.0001 \\
Return rate & 0.323 & 0.360 & -1.41 & 0.1589 \\
Return amount (JPY) & 286.78 & 245.38 & 1.34 & 0.1815 \\
\hline
\end{tabular}

Table 3. Trustor's transfer rate by category and gender

\begin{tabular}{llccc}
\hline & & Gain frame & Gain or Loss frame & Loss frame \\
\hline Female & Frequency & 20 & 26 & 63 \\
& Mean & 0.354 & 0.356 & 0.362 \\
& Median & 0.333 & 0.300 & 0.333 \\
Male & & & \\
& Frequency & 22 & 24 & 55 \\
& Mean & 0.639 & 0.293 & 0.581 \\
& Median & 0.625 & 0.267 & 0.667 \\
\hline
\end{tabular}

Table 4. Trustee's return rate by category and gender

\begin{tabular}{llccc}
\hline & & Gain frame & Gain or Loss frame & Loss frame \\
\hline Female & Frequency & 64 & 27 & 21 \\
& Mean & 0.435 & 0.335 & 0.272 \\
& Median & 0.441 & 0.333 & 0.183 \\
Male & & & \\
& Frequency & 39 & 32 & 27 \\
& Mean & 0.332 & 0.260 & 0.308 \\
& Median & 0.306 & 0.167 & 0.238 \\
\hline
\end{tabular}




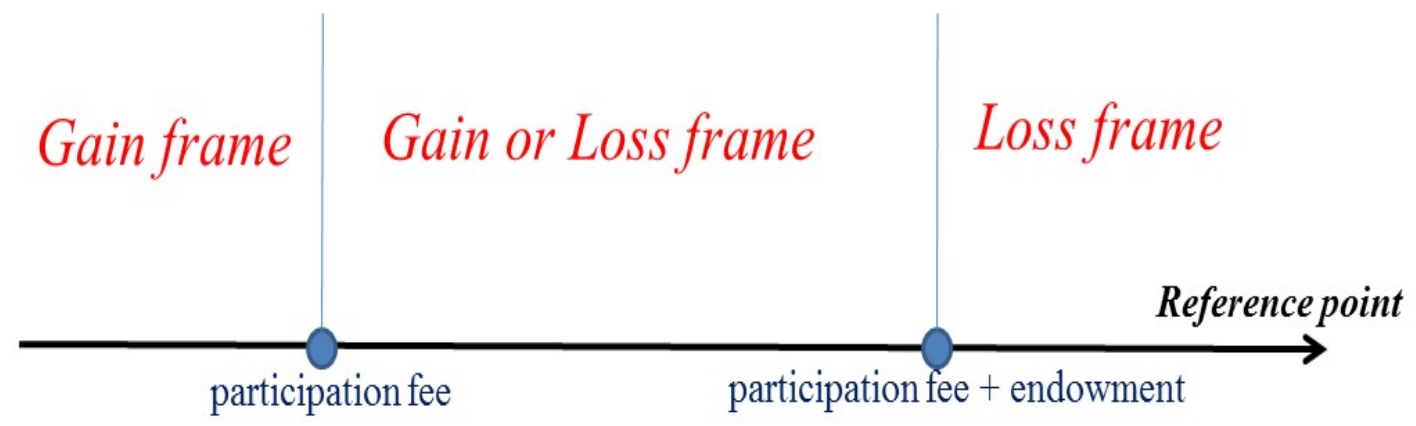

Figure 1a. Categorization of trustors by their reference points

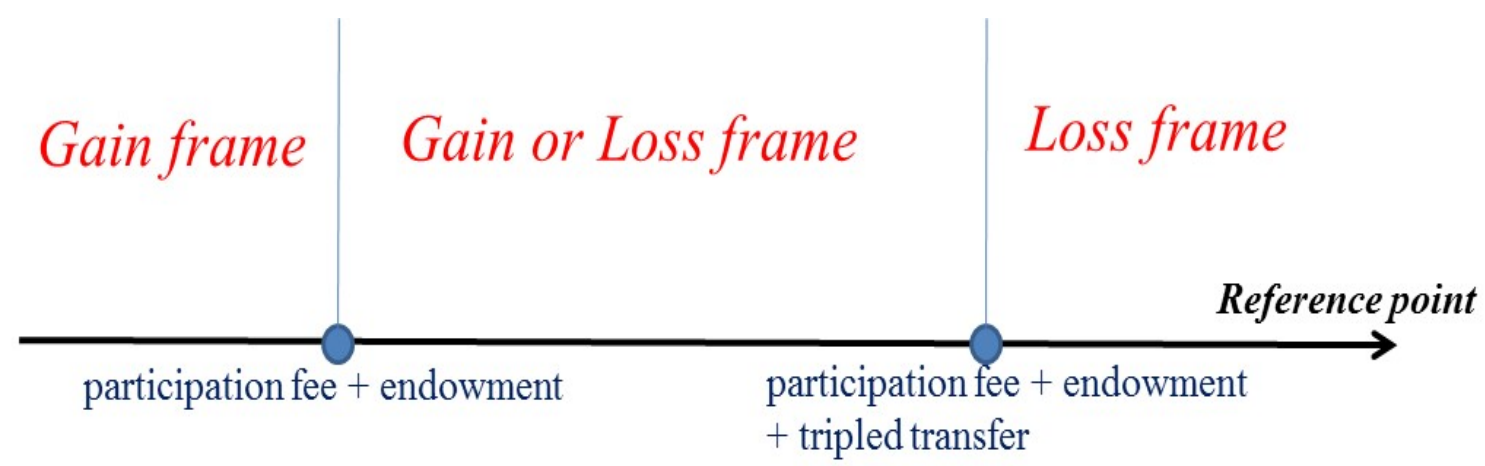

Figure 1b. Categorization of trustees by their reference points 

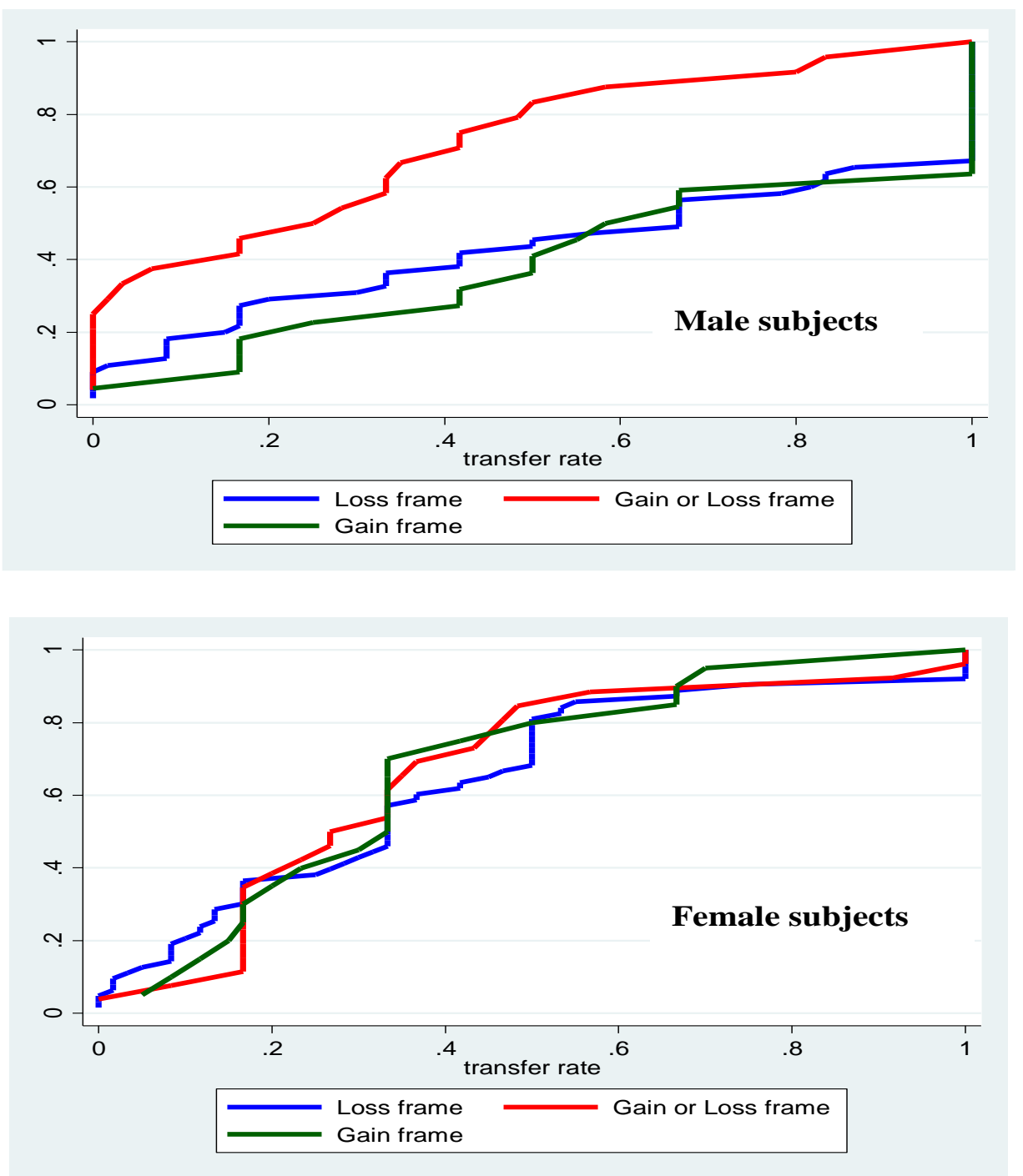

Figure 2. Cumulative distribution function of trustors' transfer rates 

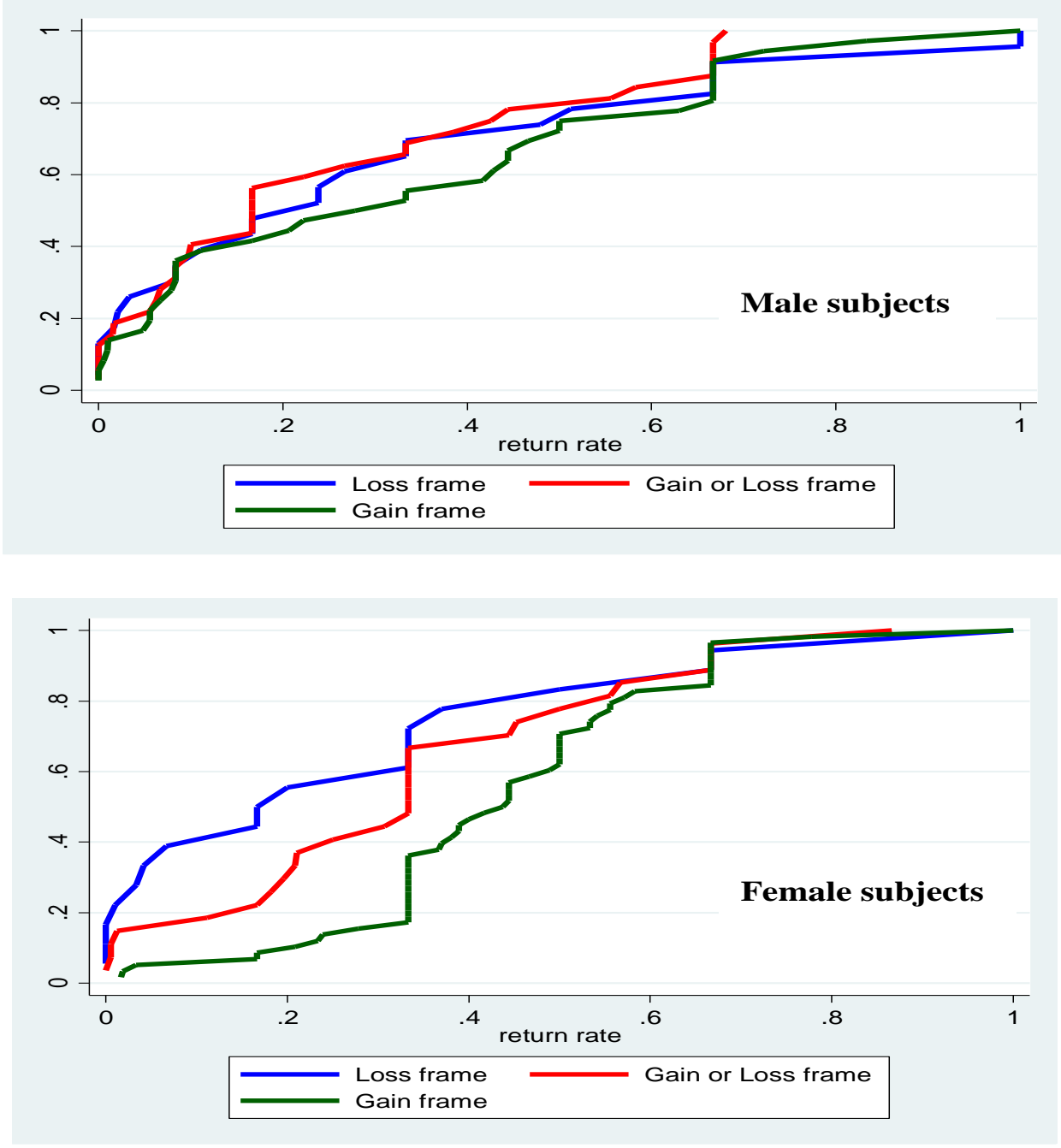

Figure 3. Cumulative distribution function of trustees' return rates 